\title{
Accelerated Strength Testing of Thermoplastic Composites
}

\author{
by J. R. Reeder*, D. H. Allen ${ }^{\dagger}$, and W. L. Bradley ${ }^{\dagger}$ \\ * NASA Langley Research Center \\ ${ }^{\dagger}$ Texas A\&M University \\ Hampton, VA 23681 \\ College Station, TX 77853
}

\begin{abstract}
Constant ramp strength tests on unidirectional thermoplastic composite specimens oriented in the $90^{\circ}$ direction were conducted at constant temperatures ranging from $149^{\circ} \mathrm{C}$ to $232^{\circ} \mathrm{C}$. Ramp rates spanning 5 orders of magnitude were tested so that failures occurred in the range from $0.5 \mathrm{sec}$. to $24 \mathrm{hrs}$. (0.5 to $100,000 \mathrm{MPa} / \mathrm{sec})$. Below $204^{\circ} \mathrm{C}$, time-temperature superposition held allowing strength at longer times to be estimated from strength tests at shorter times but higher temperatures. The data indicated that a 50\% drop in strength might be expected for this material when the test time is increased by 9 orders of magnitude. The shift factors derived from compliance data applied well to the strength results.

To explain the link between compliance and strength, a viscoelastic fracture model was investigated. The model, which used compliance as input, was found to fit the strength data only if the critical fracture energy was allowed to vary with temperature reduced stress rate. This variation in the critical parameter severely limits its use in developing a robust time-dependent strength model. The significance of this research is therefore seen as providing both the indication that a more versatile acceleration method for strength can be developed and the evidence that such a method is needed.
\end{abstract}

\section{Introduction}

Advanced polymer matrix composites are being developed for a number of elevated temperature applications. As polymeric composites are used in applications that are closer to the polymer's glass transition temperature, the compliance and strength of the material will change with time. The duration of tests that can conveniently be conducted in a laboratory will be orders of magnitude shorter than the necessary life span of composite structures. To avoid 
failures due to unexpected strength loss after long periods of time, it is imperative that accelerated tests be developed to determine long-term strength properties.

The time-temperature-superposition (TTSP) technique is a common method used to determine long-term compliance properties from shorter term tests $[1,2]$. Accelerated strength testing is not as well established. Miyano, et. al. [3, 4], suggested that it may be possible to accelerate the strength testing of advanced composite materials using time-temperaturesuperposition and shift factors obtained from creep compliance tests.

The eventual goal of this research is to develop models that are able to predict damage that will initiate and grow in materials that are in service for decades. These models will have to be able to model full thermo-mechanical fatigue accounting for viscoelastic deformation, plastic deformation, physical and chemical aging, and environmental effects. One step toward the final goal would be to accurately predict the long-term static strength of composite materials using much shorter-term strength tests. The development of such an accelerated test for strength was the objective of this research project. To accomplish this objective, tests were conducted to verify that the time-temperature superposition technique can be used with strength data and that the shift rates for strength are the same as those measured from creep compliance tests. The link between compliance and strength was then investigated in an attempt to better understand the failure mechanism so that a more robust accelerated test methodology might be developed.

Transverse tension strength of a IM7/K3B composite was tested over a wide range of time scales and at several temperatures. At each temperature, strength was determined as a function of stress rate to show the magnitude of the time-scale effect. Once the failure curves were defined at different temperatures, they were shifted to form a master curve. The formation of a master curve allowed temperature to be used as an accelerator because an elevation in temperature affected strength in a similar manner to a known increase in time scale. The shift factors were then compared to see if they were the same as the shift factors derived from compliance data.

The reason why the superposition of compliance and strength might be tied together was also investigated. A viscoelastic fracture mechanics model was formed which defined a critical 
fracture parameter based on viscoelastic compliance properties. This model was derived from a work-of-fracture model proposed by Schapery [5]. The results of the fracture model were compared to the strength results. For the fracture model to be an appropriate model for these strength tests, the strength property must be controlled by a fracture type phenomenon where cracks initiate and grow from pre-existing flaws. A model of this type, with failure based on compliance data, would not only make long-term strength prediction possible, but would also dramatically reduce the number of strength tests needed to characterize a material's strength.

\section{Experimental Testing}

Transverse strength tests were performed on IM7/K3B composite specimens at temperatures between $149^{\circ} \mathrm{C}$ and $232^{\circ} \mathrm{C}$ over a range of time scales so that time to failure ranged from $0.5 \mathrm{sec}$. to $24 \mathrm{hrs}$. During the tests, load, displacement, and strain readings were recorded. This section describes the material, test specimen, experimental apparatus, and test procedure.

\section{Material and Test Specimen}

The test material was IM7/K3B, a composite made of IM7 graphite fibers in a thermoplastic resin designated $\mathrm{K} 3 \mathrm{~B}$. The glass transition temperature $\left(\mathrm{T}_{\mathrm{g}}\right)$ of $\mathrm{K} 3 \mathrm{~B}$ has been reported to be $236^{\circ} \mathrm{C}[6]$. The high $\mathrm{T}_{\mathrm{g}}$ of the $\mathrm{K} 3 \mathrm{~B}$ resin makes IM7/K3B a candidate material in elevated temperature applications.

From the IM7/K3B prepreg material, four 8-ply unidirectional laminates measuring 30.5 $\mathrm{cm} \times 61 \mathrm{~cm}$ were prepared with the fibers running in the $61 \mathrm{~cm}$ direction. After these panels were cured using the manufacturer's recommended cure cycle, each $1.1 \mathrm{~mm}$ thick panel was cut into 30 test specimens measuring $3.8 \mathrm{~cm} \times 15 \mathrm{~cm}$ (see Figure 1a). The specimens were cut so that the fibers ran transverse to the loading direction. Three strain gauges were attached to each specimen as shown in Figure $1 \mathrm{~b}$ and were arranged so that the bending front-to-back and side-toside could be measured as well as average strain. The high temperature strain gauges designated WK-00-250BG-350 were bonded to the specimen with a high temperature strain gauge adhesive. Loading tabs were applied to each end of the specimen to reduce stress concentrations due to 
gripping. To reduce stress concentrations at the end of the tab, a relatively compliant tabbing material made of an open weave sand paper infused with an epoxy resin was used.

The specimens were dried with a multistage drying cycle lasting 24 hours with a peak temperature of $150^{\circ} \mathrm{C}$. They were then aged at $204^{\circ} \mathrm{C}$ for $4000 \mathrm{~min}$. (66 hrs.) which was significantly longer than the duration of any of the tests to be conducted. This aging cycle was conducted because the K3B resin material has been shown to physically age [6]. Physical aging in polymers occurs due to excess free volume being trapped in a polymer when cooled below $\mathrm{T}_{\mathrm{g}}$. As the polymer then moves toward equilibrium, the physical properties change. The change in the polymer matrix causes the properties of the composite to change. Although aging of this material was unavoidable, it was not the focus of this investigation. By pre-aging the specimens, the effect of the aging that occurred during the subsequent tests was reduced, thus reducing skew

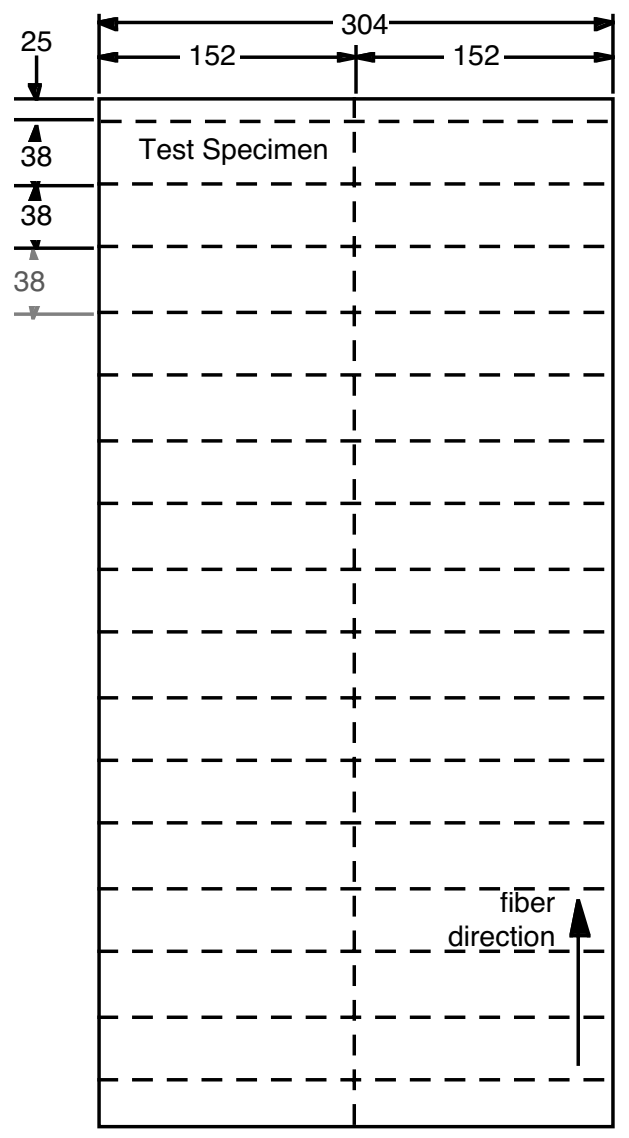

a) 8 ply laminates

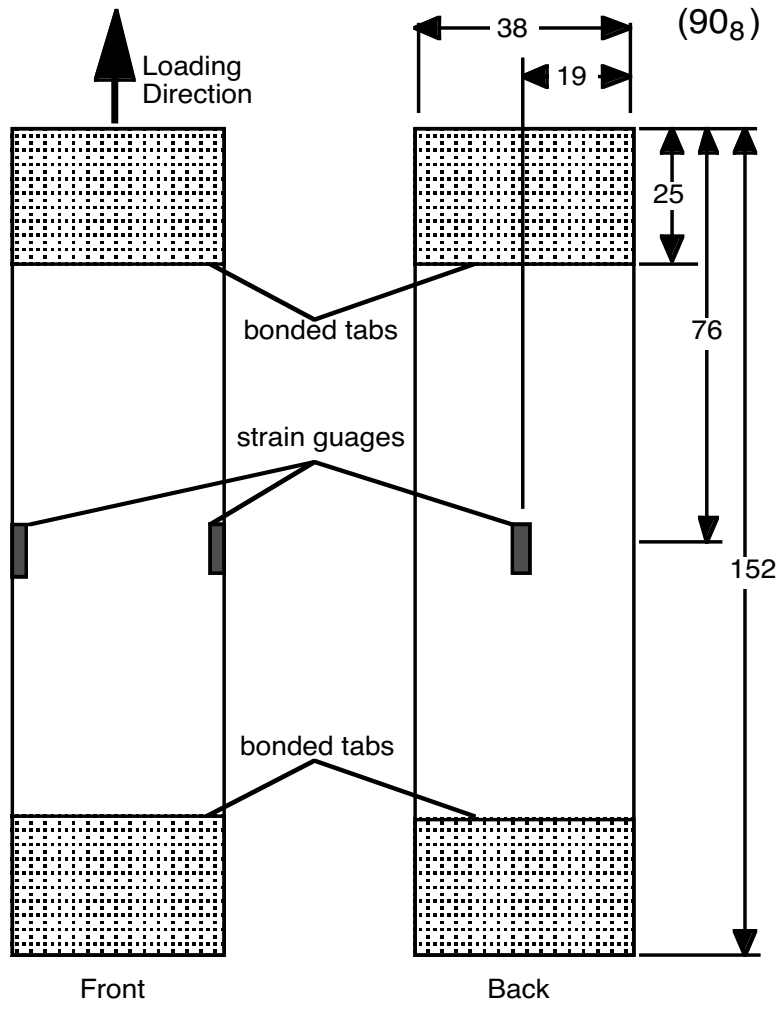

Dimensions in $\mathbf{m m}$

b) Test specimen

Figure 1. Test specimen layout on the K3B composite laminates. 
in the data for tests of different durations. To prevent moisture from re-entering the specimens, they were stored at $107^{\circ} \mathrm{C}$ for less than one week until they could be tested.

\section{Test Apparatus}

The transverse strength tests were performed in a hydraulic load machine. The test setup is presented in Figure 2. The test machine was equipped with an environmental chamber which surrounded the test section and high-temperature hydraulic wedge grips.

In addition to load and position, both temperature and strain were measured during tests. The temperatures, both inside and outside the chamber, were monitored using type $\mathrm{T}$ thermocouples. Each strain gauge was connected in a quarter bridge configuration and monitored using a bridge amplifier and meter.

All instruments were connected to the test computer. The computer collected data from the thermocouple reader, the hydraulic load frame controller and the strain gauge readers. The

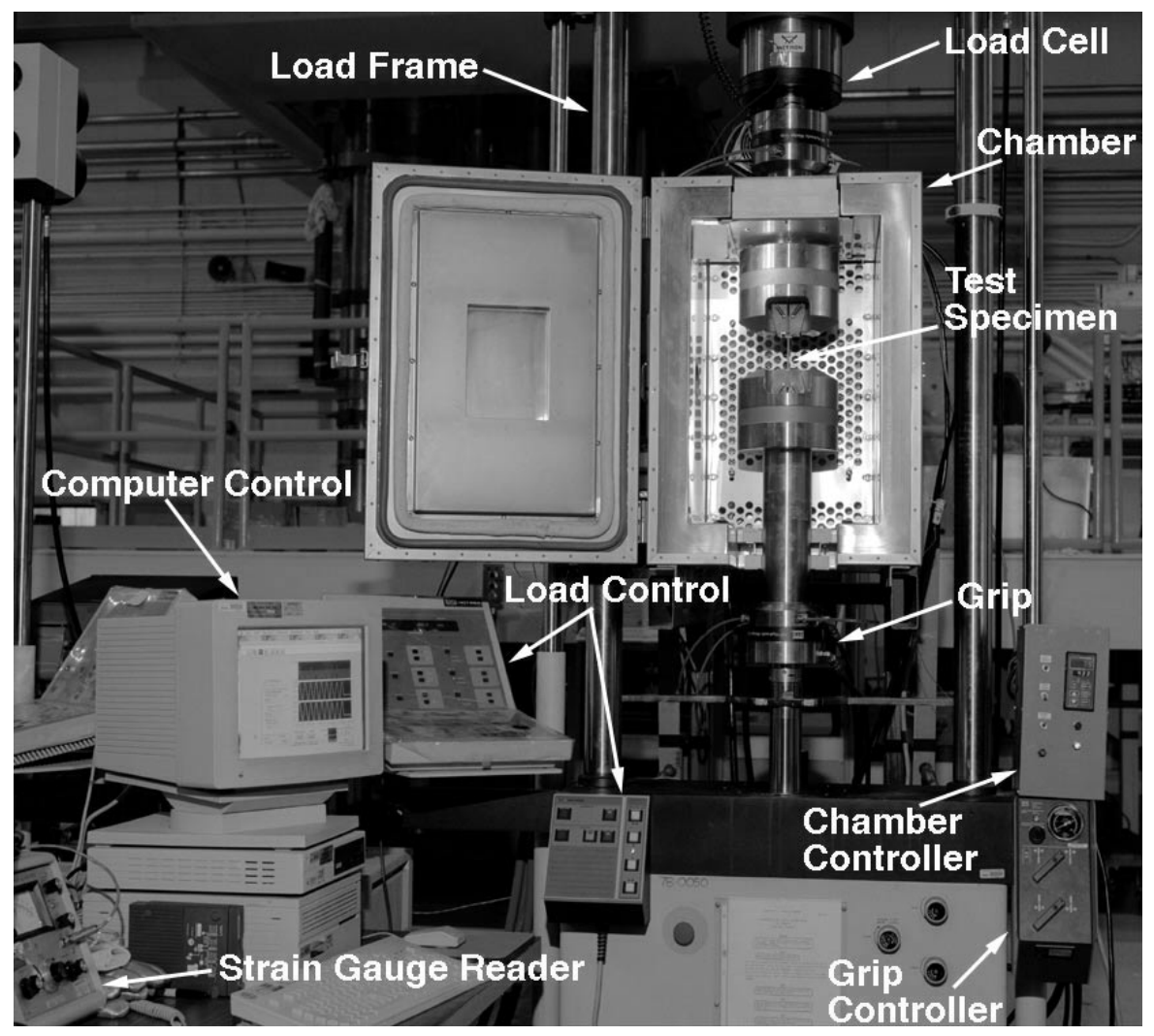

Figure 2. The test apparatus used during transverse tension tests. 
computer read, processed, plotted, and stored the data, and sent appropriate control commands to the load frame based on the processed data.

\section{Test Procedure}

Since the test specimens were cut from several panels which could be slightly different due to variations in processing, the specimen for each test was chosen using a random number generator so that the data would not be biased by such effects. The width and thickness of each specimen was measured to the nearest $2.5 \mu \mathrm{m}$ using micrometers. Measurements were taken at three different positions spaced along the length of the specimen. The average of the measurements was recorded for the thickness (b) and width (w). Strain gauges were then applied followed by the end tabs, as described earlier. The specimens were aged and stored until they could be tested. Prior to performing a test, the test chamber was heated to the test temperature and allowed to reach equilibrium temperature. This could take many hours because of the large mass of the grips. The specimen was then aligned in the grips and allowed to heat up to test temperature while hanging free from the lower grip. Thermocouples were located near each grip and at the center of the specimen to monitor temperature. Once at temperature, the strain gauges were zeroed and the bottom grip was closed. To minimize stress concentrations due to gripping, the tabs were allowed to extend out of the grips by $1 / 4$ of their length, and the grip pressure was kept as low as possible without incurring significant slip.

Transverse strength tests were performed at four temperatures: 149, 177, 204, and $232^{\circ} \mathrm{C}$. At each temperature, constant ramp rate tests were performed with a range of stress rates that produced failure times from half a second to approximately 24 hrs. The five ramp rates were $94500,4730,189,9.45$, and $0.473 \mathrm{MPa} / \mathrm{sec}$. These rates were chosen to be fairly evenly distributed when plotted on a logarithmic scale. At each stress rate and temperature, three or more duplicate tests were performed.

It was found that the zero point of the load cell could change by as much as $222 \mathrm{~N}$ due to changes in load cell temperature which changed with ambient lab temperature and with environmental chamber heating. The change in indicated load with load cell temperature was 
measured and found to be a linear function. By programming the test computer to correct the measured load for load cell temperature, the zero point was held constant within $10 \mathrm{~N}$ (less than $5 \%$ of minimum failure load). Because the load cell temperature changed very slowly, the correction was only made during tests lasting an hour or longer. The measurement of ultimate load was even more precise because a zero load reading for each test was taken just after failure. This zero point should be the same as that at failure since the time for drift in the signal was extremely small.

During a test, load, position, and the three strain gauge readings were recorded along with temperature data. At least 100 data points were recorded while each specimen was being loaded to failure.

After each test, average specimen strain as well as the difference in strain readings frontto-back and side-to-side were calculated and plotted as a function of load. The side-to-side and front-to-back bending strains generally stayed below $200 \mu \varepsilon$ which is less that $5 \%$ of the average strain at failure and indicates that the specimens were well aligned. The specimen strength was determined by dividing the maximum load value by the specimen area (the product of average width and average thickness for each specimen).

\section{Analysis}

This section describes three different analytical models. The first model produces an expression for the compliance of the K3B matrix material as a function of time and temperature. This will be used as input for the subsequent models. The second model predicts composite compliance transverse to the fiber direction and is used in the results section to verify the accuracy of the matrix model. The third model is a viscoelastic fracture model which relates the matrix compliance properties to composite failure. This model attempts to explain the link between the time-temperature effects of compliance and strength and therefore is an attempt at developing a robust accelerated test method. 


\section{Matrix Compliance Model}

The model for the compliance of the matrix $\left(\mathrm{D}_{\mathrm{m}}\right)$ is based on creep data for the K3B material collected during a study on physical aging [6]. The data from the reference were in the form of momentary master curves shown as dashed curves in Figure 3. Each momentary master curve was constructed with data from several creep tests conducted at different aging times, but with the data adjusted to represent compliance at a constant reference aging time. The reference time used in producing these momentary master curves was $2 \mathrm{hr}$.

To make predictions of compliance for longer testing times than could actually be performed, the time temperature superposition (TTSP) technique was used. In this technique the dashed curves are shifted horizontally to form a TTSP master curve as shown by the solid line. For this master curve, all the data were shifted to a reference temperature of $200^{\circ} \mathrm{C}$. A horizontal shift in data has the effect of shifting the data in time, and the distance that each curve must be shifted is recorded as the shift factor $\left(\mathrm{A}_{\mathrm{T}}\right)$, for that temperature. The master curve was fitted with a stretched exponential function which has the form

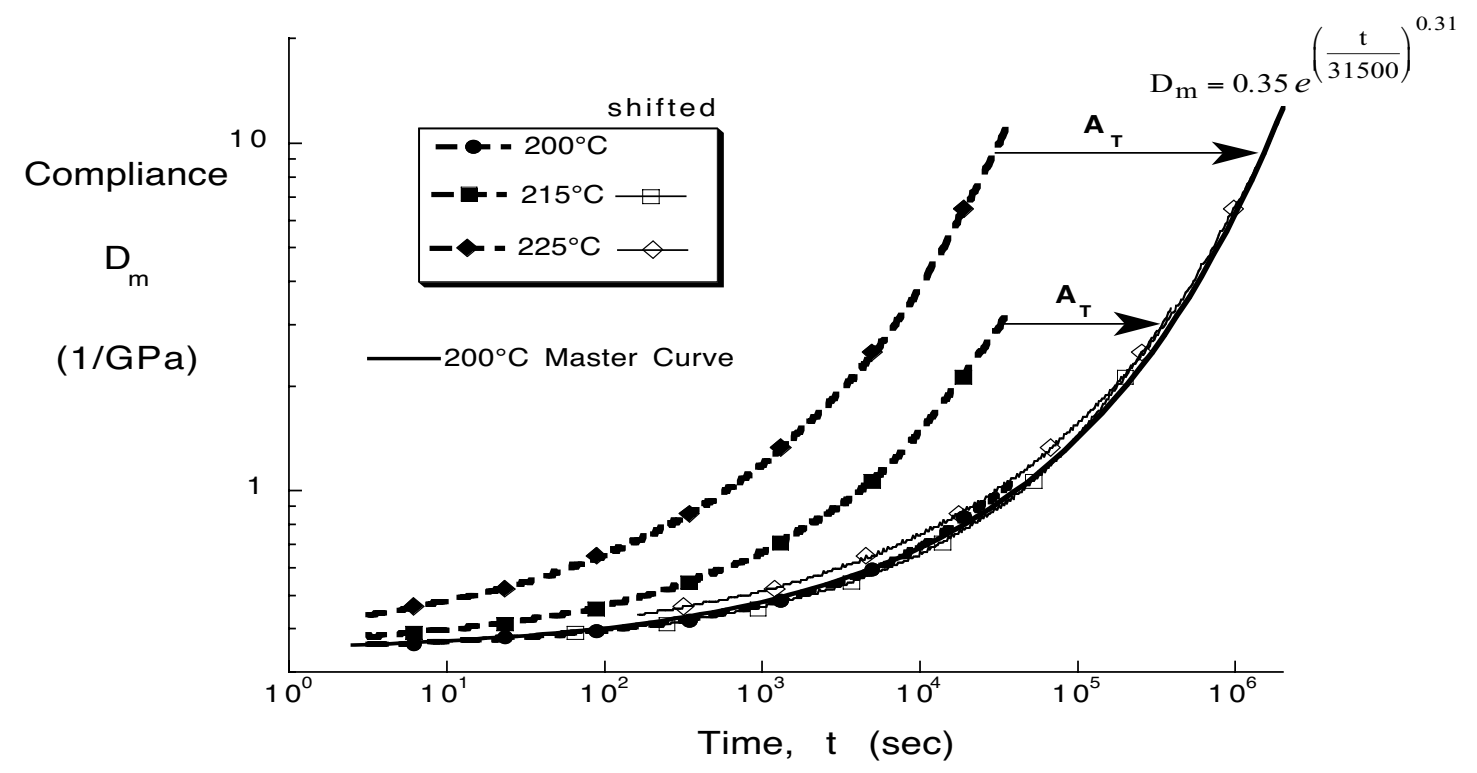

Figure 3. Time-temperature compliance master curve for K3B matrix. 


$$
D_{m}=D_{o} e^{\left(\frac{t}{\tau}\right)^{\beta}}
$$

The curve fit parameters: initial compliance $\left(D_{0}\right)$, time constant $(\tau)$, and stretch factor $(\beta)$ have values of $0.3551 / \mathrm{GPa}, 31500 \mathrm{sec}$., and 0.31 , respectively. To use the master curve at a temperature other than the reference temperature the curve must be shifted horizontally using an appropriate shift factor. The relationship between temperature and shift factor is derived from the shift factors determined in developing the master curve. Figure 4 shows that the relationship between $A_{T}$ and temperature is well modeled by an Arrhenius style equation [7] of the form

$$
\log \mathrm{A}_{\mathrm{T}}=\eta\left(\frac{1}{\mathrm{~T}_{\mathrm{K}}}-\frac{1}{\mathrm{~T}_{\mathrm{o}}}\right)
$$

with a shift rate $(\eta)$ of $16500^{\circ} \mathrm{K}$ (corresponding to an activation energy of $316 \mathrm{~kJ} / \mathrm{mole}$ ). The reference temperature of the master curve $\left(\mathrm{T}_{\mathrm{o}}\right)$ and the temperature to which the data should be shifted $\left(\mathrm{T}_{\mathrm{K}}\right)$ must both be expressed in absolute units. Since this master curve is at $200^{\circ} \mathrm{C}, \mathrm{T}_{\mathrm{o}}=$

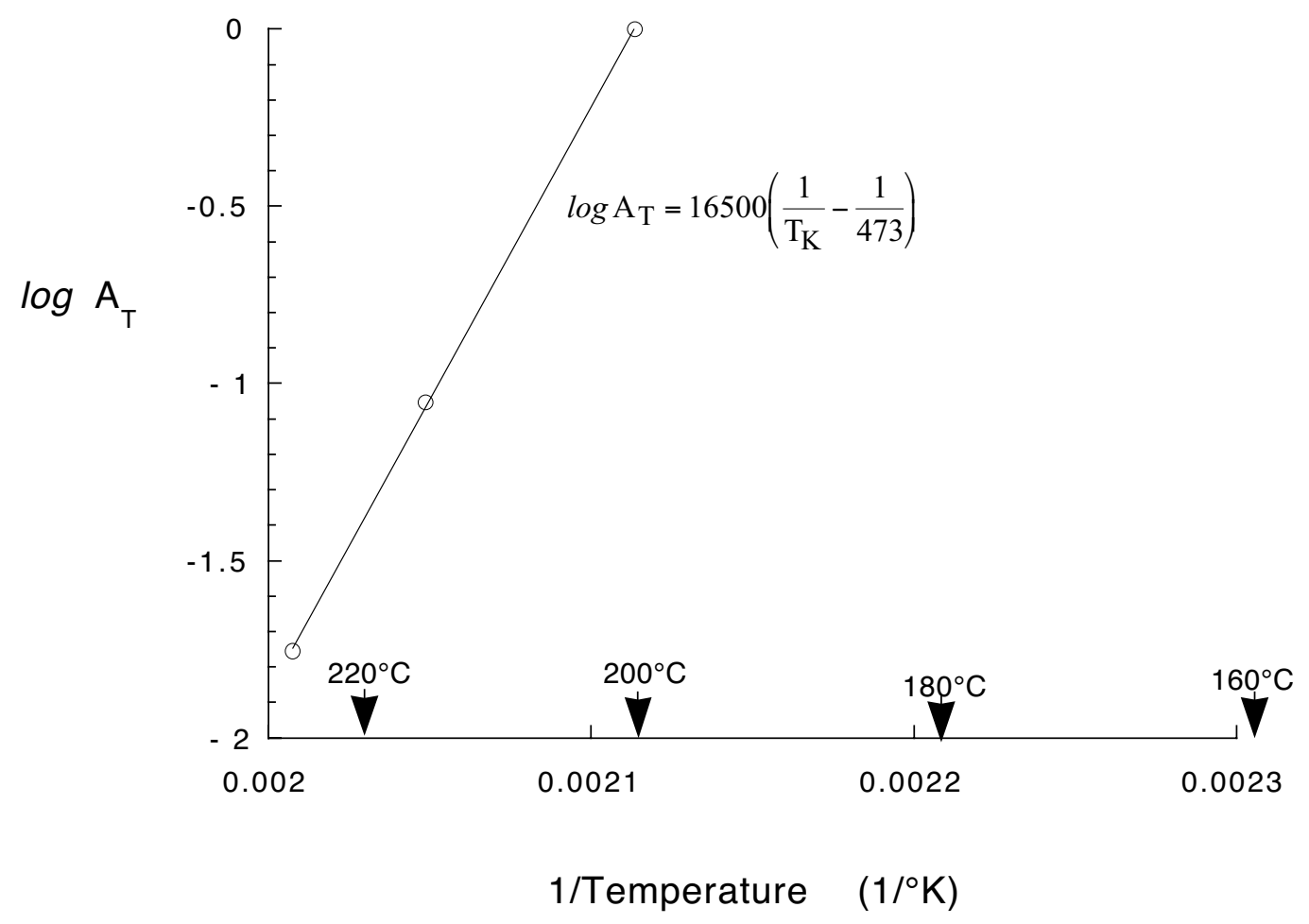

Figure 4. Shift factors from K3B master curve. 
$473^{\circ} \mathrm{K}$. Equations 1 and 2 can then be combined to obtain the following expression for compliance as a function of time and temperature.

$$
\mathrm{D}_{\mathrm{m}}=\mathrm{D}_{\mathrm{o}} e^{\left(\frac{\mathrm{t}}{\tau 10^{-\eta\left(1 / \mathrm{T}_{\mathrm{K}}-1 / \mathrm{T}_{\mathrm{o}}\right)}}\right)^{\beta}}
$$

One more correction was needed before this model could be used to predict the compliance of the matrix of the composite specimens used in this study. The compliance curves presented in Figure 3 were for resin material with a constant aging time of 2 hours $\left(t_{\text {ref }}\right)$. The composites in this study were aged for $66 \mathrm{hrs}$. at $204^{\circ} \mathrm{C}$. The additional aging time will have affected the compliance properties so it must be accounted for. Aging time can be accounted for by shifting the master curve just as the TTSP technique shifts the master curve to account for temperature. The following equation relates the shift factor for aging $\left(a_{T}\right)$ to the aging time $\left(t_{\text {age }}\right)$.

$$
\log \left(\mathrm{a}_{\mathrm{T}}\right)=\mu\left(\log \left(\mathrm{t}_{\mathrm{age}}\right)-\log \left(\mathrm{t}_{\mathrm{ref}}\right)\right)
$$

From reference 6 the shift rate $(\mu)$ for aging at $204^{\circ} \mathrm{C}$ was found to be 0.93 . Aging $66 \mathrm{hrs}$. at $204^{\circ} \mathrm{C}$ therefore caused an aging shift factor $\left(\mathrm{a}_{\mathrm{T}}\right)$ of 26.0. To shift the reference master curve, $\mathrm{a}_{\mathrm{T}}$ was multiplied by the time constant $(\tau)$. Incorporating the aging shift factor into Equation 3 produced the following compliance model for the K3B matrix using the numerical values found in Table 1.

\begin{tabular}{|c|c|}
\hline Parameter & Value \\
\hline $\mathrm{D}_{\mathrm{o}} \quad$ Initial compliance & $0.3551 / \mathrm{GPa}$ \\
\hline $\begin{array}{ll}a_{\mathrm{T}} & \text { Aging shift factor }\end{array}$ & 26.0 \\
\hline$\tau \quad$ Time constant & $31500 \mathrm{sec}$ \\
\hline$\eta \quad$ TTSP shift rate & $16500{ }^{\circ} \mathrm{K}$ \\
\hline $\mathrm{T}_{\mathrm{o}}$ Reference temperature & $473^{\circ} \mathrm{K}$ \\
\hline$\beta \quad$ Exponential stretch factor & 0.31 \\
\hline
\end{tabular}

Table 1. Matrix compliance model property values. 


$$
D_{m}=D_{0} e^{\left(\frac{t}{a_{T} \tau 10^{-\eta\left(1 / T_{K}-1 / T_{0}\right)}}\right)^{\beta}}
$$

\section{Composite Compliance Model}

The composite compliance model was used to relate the matrix compliance model to the composite stress-strain response which was measured during this study. The matrix compliance was related to the compliance of the composite through a simple series model.

$$
\mathrm{D}_{\mathrm{c}}=v_{\mathrm{f}} \mathrm{D}_{\mathrm{f}}+v_{\mathrm{m}} \mathrm{D}_{\mathrm{m}}
$$

where $\mathrm{D}$ and $v$ were respectively the compliance and volume fraction of the composite, fiber, and matrix. Because the matrix is much more compliant than the fiber in this type of graphitepolymer composite, the fiber was assumed to be rigid $\left(D_{\mathrm{f}}=0\right)$. Equation 6 therefore reduced to

$$
\mathrm{D}_{\mathrm{c}}=v_{\mathrm{m}} \mathrm{D}_{\mathrm{m}}
$$

This, the simplest of composite micromechanics models, will be shown to be adequate for the purposes of this research. Equation 7 indicates that a simple scaling factor should be able to scale the matrix compliance to that of the composite, and further that the scaling factor would have physical significance as the matrix volume fraction.

Figure 5 shows the stress-strain response of a transverse tension composite specimen tested at $149^{\circ} \mathrm{C}$ and $2220 \mathrm{~N} / \mathrm{sec}$ and the prediction of the matrix compliance model for a neat resin specimen tested under the same conditions. At this low temperature and high stress rate, the material behaved essentially linear elastically, producing a linear stress-strain curve. The figure shows that a scaling factor of 0.33 was needed to scale the predicted neat resin response to the measured response of the composite thus creating a composite compliance model. The composite compliance was then used to model the composite material at test conditions where the material exhibited viscoelasticity.

A hereditary integral [8], given as Equation 8, was used to predict the strain response due to a given loading history based on the material's viscoelastic compliance. 


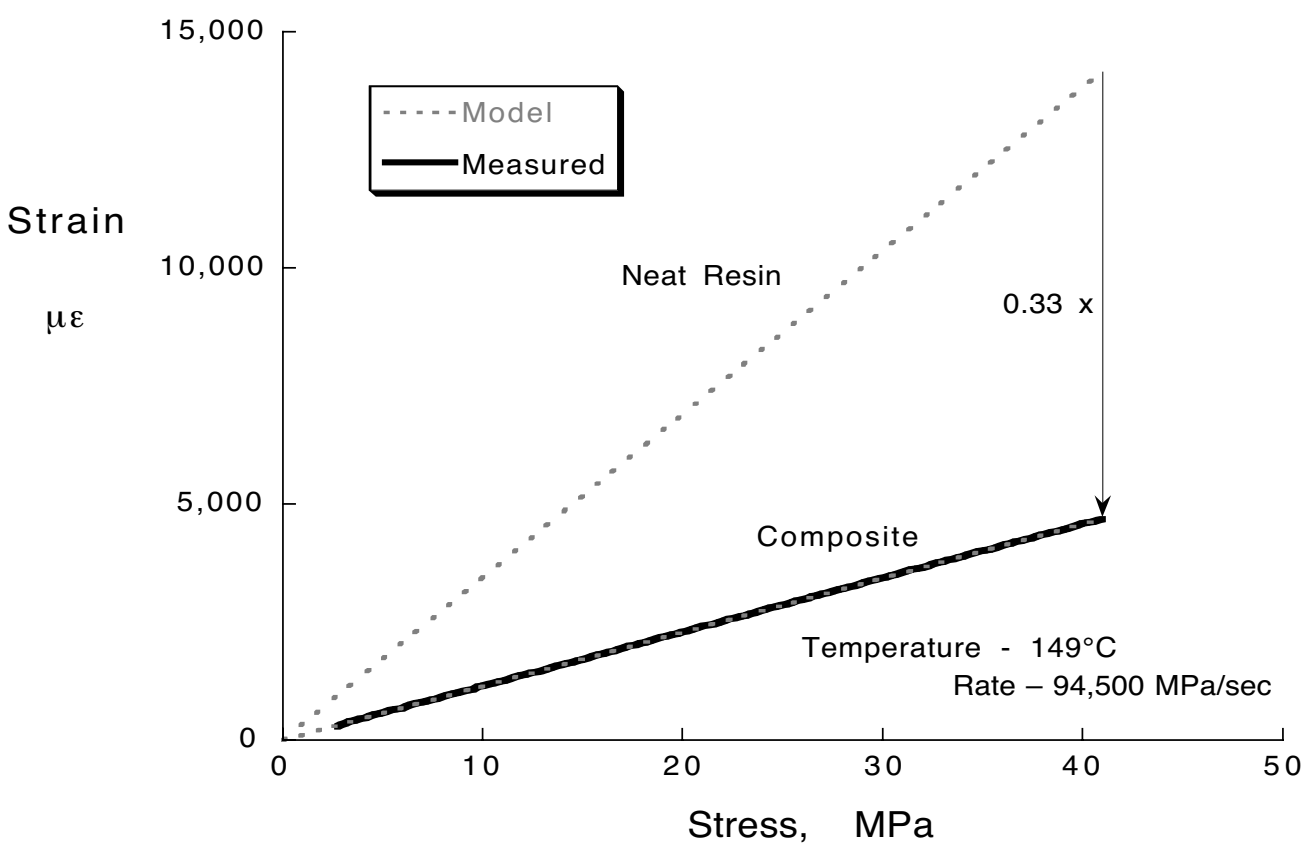

Figure 5. Scaling of matrix compliance.

$$
\varepsilon(t)=\int_{0}^{t} D(t-\psi) \frac{d \sigma(\psi)}{d \psi} d \psi
$$

Stress and strain are given by $\sigma$ and $\varepsilon$, respectively and $\psi$ is a dummy time variable. In Equation 8 , D can be the compliance of the matrix or the composite depending on which material response is to be modeled.

\section{Viscoelastic Fracture Model}

To help explain the transverse strength results which will be presented, a fracture model was considered. The use of a fracture model assumed that specimen failure was precipitated by a pre-existing flaw which initiated a crack that grew quickly to failure. Many different parameters have been used to describe when a crack will extend. The three most notable are K, G, and J [9]. The stress intensity factor $(\mathrm{K})$ is a scaling factor to describe the magnitude of the stress field around a crack tip. The strain energy release rate $(\mathrm{G})$ describes the amount of energy made available to the crack tip from external forces and internal strain energy when the crack length is 
extended. The J-integral is an alternative method of evaluating the energy released as a crack grows which can account for plasticity in the body. The J-integral is calculated by a path independent integral of traction, displacement and strain energy, around the crack tip. For linear elastic problems, the three parameters are related to each other by material properties and therefore predictions made from them are equivalent. Fracture in a viscoelastic body is more complicated.

The $G$ parameter assumes that the energy supplied to a cracked body is readily available to extend the crack. This is not the case in a viscoelastic body where some of the absorbed energy may require significant amounts of time to be released. The $\mathrm{W}_{\mathrm{f}}$ fracture parameter describes only the amount of energy that can be released by a viscoelastic body at a given point in time. Schapery [5] used a path independent integral and the elastic-viscoelastic correspondence principle to develop the expression for $\mathrm{W}_{\mathrm{f}}$ given in Equation 9.

$$
\mathrm{W}_{\mathrm{f}}=\mathrm{E} \int_{\mathrm{t}_{\mathrm{o}}}^{\mathrm{t}_{\mathrm{i}}} \mathrm{D}^{\prime}\left(\mathrm{t}_{\mathrm{i}}-\Psi\right) \frac{\mathrm{d} J^{\mathrm{E}}}{\mathrm{d} \Psi} \mathrm{d} \Psi
$$

where $\mathrm{J}^{\mathrm{E}}$ is the J-integral for an elastic body similar to the viscoelastic body of interest but with a constant modulus, E. The E value is actually arbitrary because it eventually cancels out of the equation. The effective compliance, $\mathrm{D}^{\prime}$, is a complex function of the orthotropic compliance of the composite [10]. For the polymer matrix composite used in this study, where the viscoelastic matrix is soft in comparison to the elastic fiber, $\mathrm{D}^{\prime}$ will be assumed to be proportional to the compliance of the matrix as indicated in Equation 10.

$$
D^{\prime}(t)=C_{1} D_{m}(t)
$$

The integral is from the initiation of loading $\left(t_{0}\right)$ to the time when the crack begins to grow $\left(t_{i}\right)$. Since $\mathrm{J}^{\mathrm{E}}$ is for the reference elastic system, it is equivalent to $\mathrm{G}^{\mathrm{E}}$, the strain energy release rate of the reference system and related to K through the reference modulus and the Poisson's ratio (v) as shown in Equation 11. The stress intensity factor is only a function of the applied stress 
$(\sigma)$ and the geometry parameters such as crack size and specimen dimensions which are represented by a constant $\left(\mathrm{C}_{2}\right)$.

$$
\mathrm{J}^{\mathrm{E}}=\mathrm{G}^{\mathrm{E}}=\frac{1-v^{2}}{\mathrm{E}} \mathrm{K}^{2}=\frac{1-v^{2}}{\mathrm{E}}\left(\mathrm{C}_{2} \mathrm{\sigma}\right)^{2}
$$

Substituting Equation 11 into the Equation 9 yields

$$
\mathrm{W}_{\mathrm{f}}=\left(1-v^{2}\right) \mathrm{C}_{1} \mathrm{C}_{2}^{2} \int_{\mathrm{t}_{\mathrm{o}}}^{\mathrm{t}_{\mathrm{i}}} \mathrm{D}_{\mathrm{m}}\left(\mathrm{t}_{\mathrm{i}}-\Psi\right) \frac{\mathrm{d}\left(\sigma^{2}\right)}{\mathrm{d} \Psi} \mathrm{d} \Psi
$$

For an elastic body, $\mathrm{W}_{\mathrm{f}}$ can be shown to be equal to $\mathrm{J}^{\mathrm{E}}$ and $\mathrm{G}^{\mathrm{E}}$ since $\mathrm{D}$, which is not a function of time, can be moved out of the integral in Equation 9 and since 1/D=E.

Although it is not necessary that $\mathrm{W}_{\mathrm{f}}$ be constant with time and temperature, if one does make that assumption, prediction of failure as a function of time and temperature becomes very straight forward. One could test a specimen geometry for which the strain energy release rate constant $\left(\mathrm{C}_{2}\right)$ is known. From Equation 12, the critical value of $\mathrm{W}_{\mathrm{f}}$ could then be calculated using the time to failure and the other test parameters. The critical $\mathrm{W}_{\mathrm{f}}$ could then be used to calculate the time to failure of any other loading history and geometry by inverting Equation 12. Of course the $\mathrm{C}_{2}$ parameter would need to be known for the new geometry.

In the current application, the size and shape of the critical flaw was not known resulting in an unknown value of $\mathrm{C}_{2}$. To use the model for this case, $\mathrm{C}_{2}, \mathrm{~W}_{\mathrm{f}}$, and material properties that were assumed constant in the current study were grouped together to define one unknown constant. Once this constant was determined by a single strength test, the fracture model was used to predict strength after other loading and temperature histories. Although the unknown $\mathrm{C}_{2}$ limits the model predictions to similar geometries, the model was still quite useful because failure predictions due to a wide range of loading and temperature histories were possible.

The experiments in this study were performed with constant stress rates (R); therefore

$$
\sigma=\mathrm{Rt}
$$

This expression was then substituted into Equation 12, to obtain 


$$
\begin{aligned}
\mathrm{W}_{\mathrm{f}} & =\left(1-v^{2}\right) \mathrm{C}_{1} C_{2} \int_{\mathrm{t}_{\mathrm{o}}}^{\mathrm{t}_{\mathrm{i}}} \mathrm{D}_{\mathrm{m}}\left(\mathrm{t}_{\mathrm{i}}-\Psi\right) \frac{\mathrm{d}\left(\mathrm{R}^{2} \psi^{2}\right)}{\mathrm{d} \Psi} \mathrm{d} \Psi \\
& =2\left(1-v^{2}\right) \mathrm{C}_{1} \mathrm{C}_{2}^{2} \mathrm{R}^{2} \int_{\mathrm{t}_{\mathrm{o}}}^{\mathrm{t}_{\mathrm{i}}} \Psi \mathrm{D}_{\mathrm{m}}\left(\mathrm{t}_{\mathrm{i}}-\Psi\right) \mathrm{d} \Psi
\end{aligned}
$$

Equation 15 was derived by assuming that $\mathrm{W}_{\mathrm{f}}$ is constant and collecting the terms that are constant for this study:

$$
\mathrm{R}^{2} \int_{\mathrm{t}_{\mathrm{o}}}^{\mathrm{t}_{\mathrm{i}}} \Psi \mathrm{D}_{\mathrm{m}}\left(\mathrm{t}_{\mathrm{i}}-\Psi\right) \mathrm{d} \Psi=\frac{\mathrm{W}_{\mathrm{f}}}{2\left(1-v^{2}\right) \mathrm{C}_{1} \mathrm{C}_{2}^{2}}=\text { Constant }
$$

Once the critical value of this constant was determined from a "reference" strength test, predictions of failure could be made for other temperature and load histories. Figure 6 shows predictions of this model created by inverting Equation 15 to predict times to failure at different stress rates and temperatures, using Equation 5 as the expression for matrix compliance $\left(D_{m}\right)$ and the experimentally measured failure stress at $149^{\circ} \mathrm{C}$ and $94500 \mathrm{MPa} / \mathrm{sec}$ as the reference strength. Although Figure 6 only shows predictions for constant stress rate tests, failures due to other loading histories could have been predicted. A mathematical manipulation computer program was used to create the contour plots in Figure 6 because inverting the integral in Equation 15 to obtain a closed form expression for $t_{i}$ as a function of $R$ and $D_{m}$ was not possible. Figure 6 actually shows predictions of strength (the product of $t_{i}$ and $R$ ) versus stress rate to emulate how experimental results might actually be presented. 
Figure 6 shows that the model predicts strength decreasing with longer test times or slower ramp rates. One way of thinking about the results is to think of a failure occurring at a given stress level. If the time to reach that stress level were to be increased, the time for viscoelastic deformation would also be increased, therefore producing greater deformation. The model assumes that the work to failure is constant; therefore if the deformation increases, the critical stress would have to decrease since work is the product of stress and deformation.

Without assuming that $\mathrm{W}_{\mathrm{f}}$ remains constant with time and temperature, the predictive capabilities of the model become much more limited. Instead of being able to predict a wide range of failure events with just one test, many would be needed. Once the failure envelope for how $\mathrm{W}_{\mathrm{f}}$ changes with histories of load and temperature is defined for one specimen geometry, it could then be used to predict the failure of other geometries. Since the variety of load and temperature histories to failure are unlimited, defining the failure envelope would be problematic without further understanding of how $\mathrm{W}_{\mathrm{f}}$ should change. The $\mathrm{W}_{\mathrm{f}}$ model would still be quite useful for making predictions of failure for some complicated structure based on a coupon test conducted

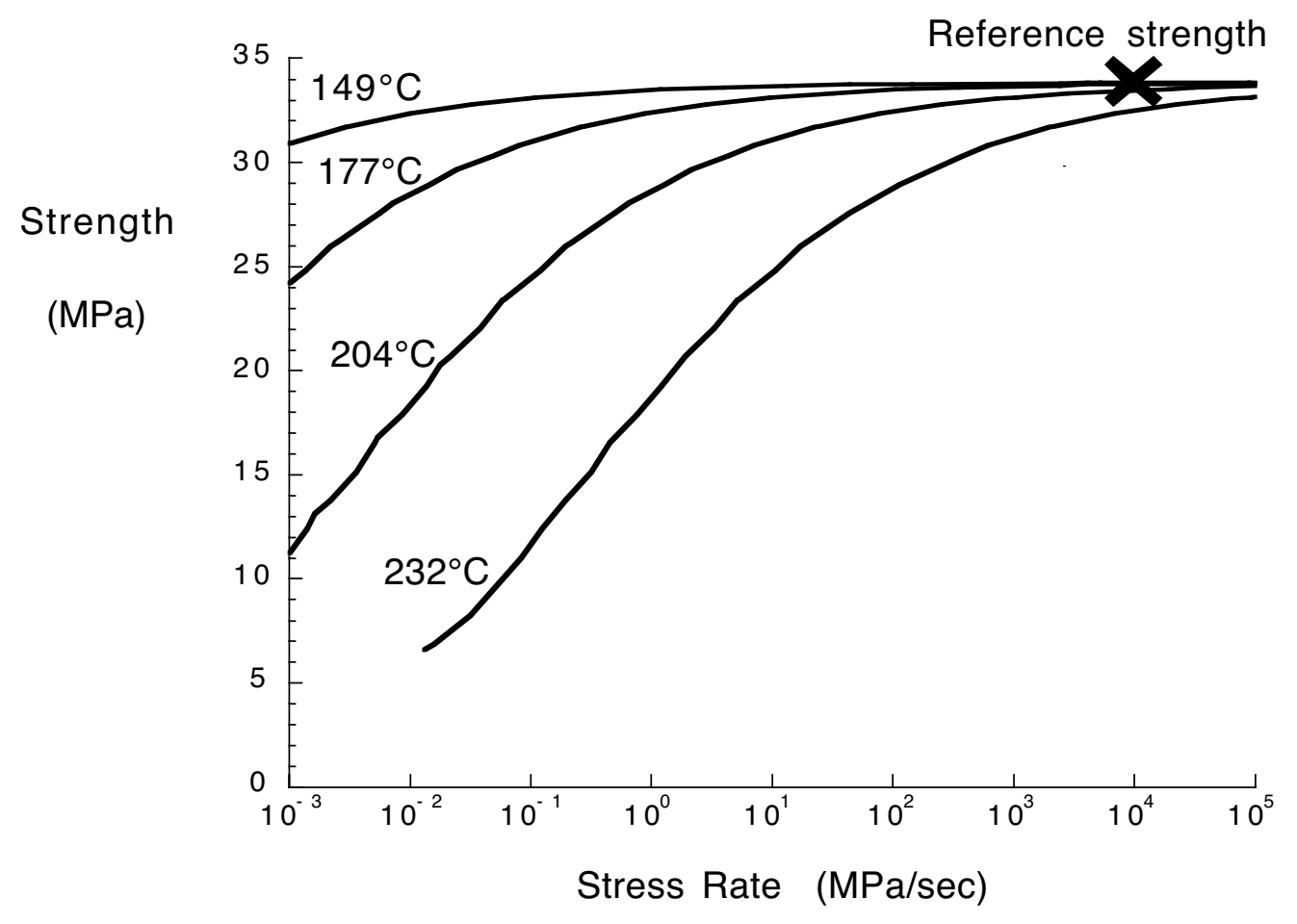

Figure 6. Constant $\mathrm{W}_{\mathrm{f}}$ contours of strength predictions. 
such that the history of $\mathrm{W}_{\mathrm{f}}$ for the critical flaw was duplicated in an accelerated mode by increasing the temperature.

\section{Results and Discussion}

This section presents the results of the transverse strength tests conducted over a range of temperatures and stress rates and compares the results to predictions from the various models.

\section{Strength Results}

Strength tests were performed at four different temperatures and at stress rates that varied by 5 orders of magnitude. The results of these tests are plotted in Figure 7. Numerical values for all data points are listed in reference 11. There is a large amount of scatter in the data which blurs the effect of stress rate and temperature, but scatter is a common problem for this type of transverse tension specimen [12]. The scatter is believed to be due to the premature failure of some of the specimens. The strength of a test specimen may be artificially low for many reasons: specimen misalignment, damage caused during specimen machining, stress

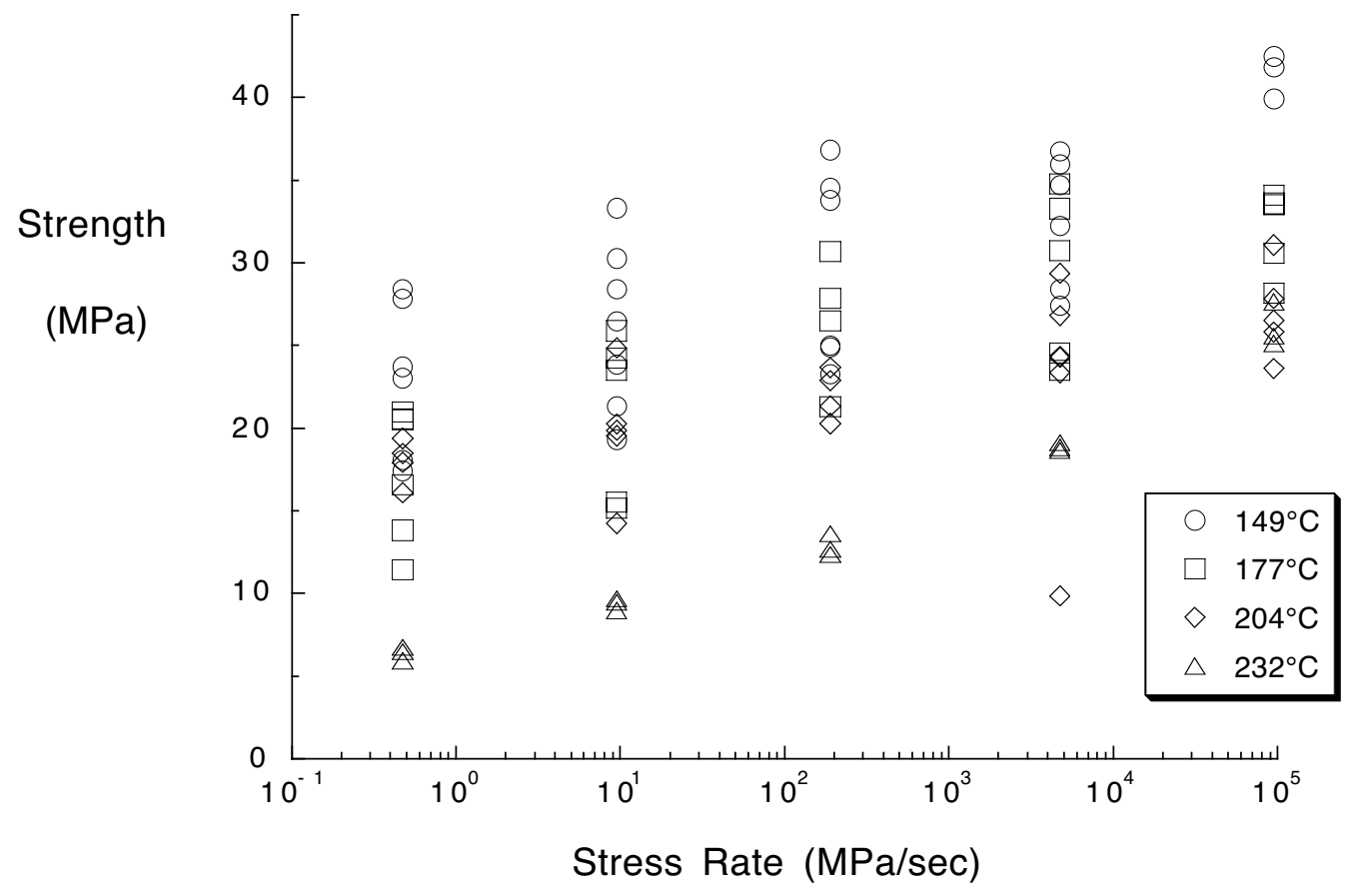

Figure 7. Results of transverse tension tests on K3B/IM7. 
concentration due to gripping, etc. Because there are many reasons that would cause a specimen strength to be abnormally low and no anticipated reason that would cause a specimen to show an artificially high strength, only the highest three strength values at each test condition were used in the rest of this study. The strength results are replotted in Figure 8 with the lower strength values filtered out. It is obvious that not only is the scatter greatly reduced, but trends in the data can be much more readily seen. Most of the strength results that were filtered out, were from specimens that failed at the grip line while others were from specimens with noticeable edge defects, but not all the rejected data showed signs of problems. Of the data that were kept, some specimens failed at the grip line which can be a sign of early failure due to stress concentrations but can also naturally occur due to random strength variations along the length of the specimen. In Figure 8, the trends in the data are marked by second order polynomial curves fitted through the data by a least squares procedure. At each temperature, the strength decreased by at least $25 \%$ as the test time was increased by 5 orders of magnitude. At $232^{\circ} \mathrm{C}$, which was the temperature at which the strength was the most sensitive to stress rate, the strength dropped by $66 \%$. The highest strength was always at the highest stress rate and therefore the shortest test.

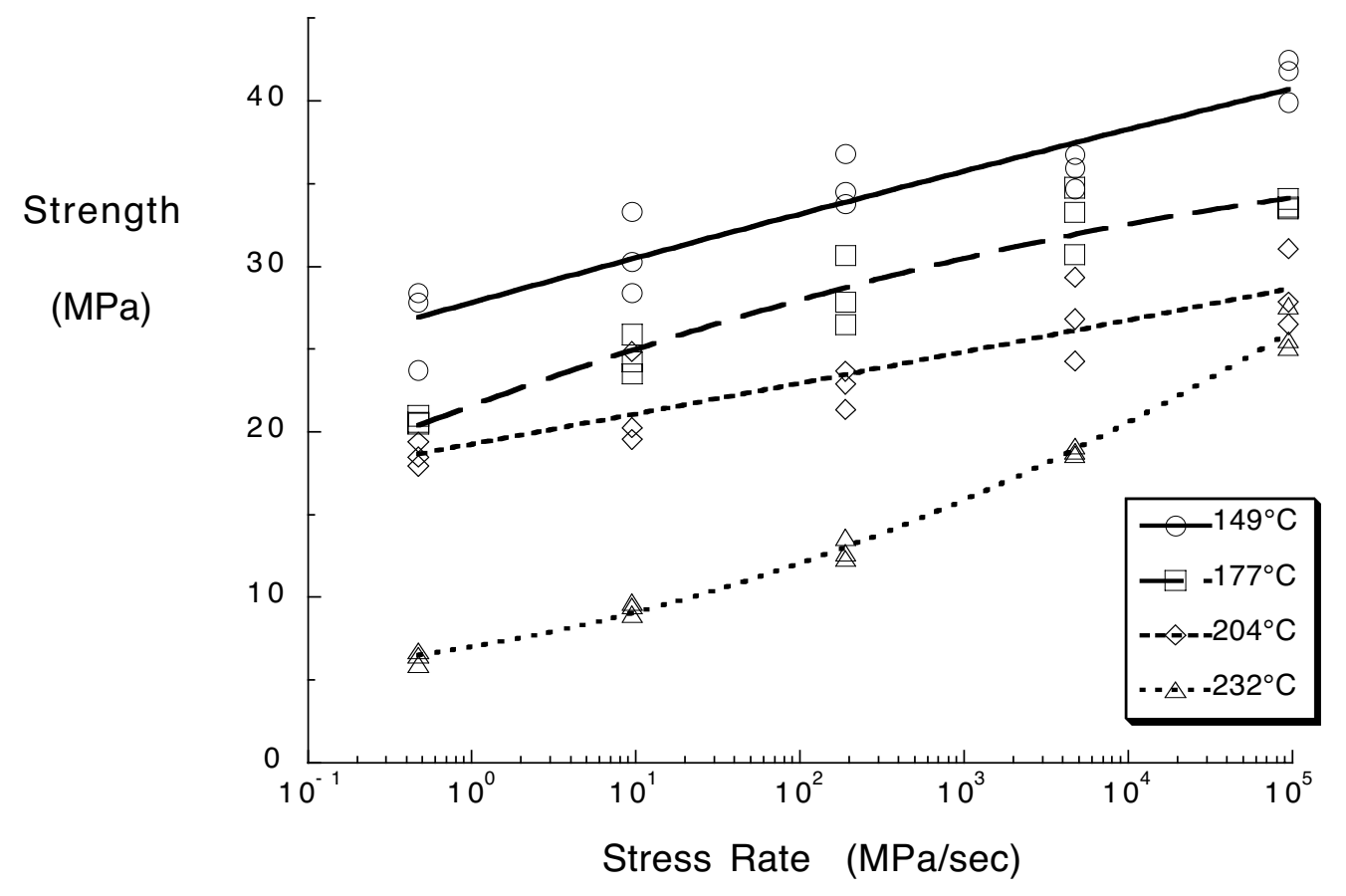

Figure 8. Filtered IM7/K3B transverse strength results (highest 3 strengths at each condition). 
The strength results also showed a significant temperature dependence. Each increment of $28^{\circ} \mathrm{C}$ reduced the strength at a given stress rate by an average of $6.2 \mathrm{MPa}$. The form of the curves are such that they might be shifted to form a master curve. Figure 9 was created by shifting the results presented in Figure 8 using the same shift constant $\left(\eta=16500^{\circ} \mathrm{K}\right)$ that created the matrix compliance master curve shown in Figure 3. In Figure 9, strength is plotted against "temperature reduced" stress rate indicating that data at different temperatures were shifted in time. The shift factors, $A_{T}$, are given by Equation 2 . However for the strength data, the reference temperature, $\mathrm{T}_{\mathrm{o}}$, was chosen as $422^{\circ} \mathrm{K}\left(149^{\circ} \mathrm{C}\right)$ corresponding to the minimum temperature tested, as opposed to $\mathrm{T}_{\mathrm{o}}=473^{\circ} \mathrm{K}$ which had been used with compliance data. Since the shift factor at $149^{\circ} \mathrm{C}$ is 1 , the plot can be thought of as the master curve at $149^{\circ} \mathrm{C}$ plotted against stress rate. In Figure 9, only the averages of the high 3 replicate tests are shown. The light lines are the best fit lines from the previous figure shifted in time. The strength results up to $204^{\circ} \mathrm{C}$ do appear to form a fairly well behaved master curve as shown by the heavy line. At $232^{\circ} \mathrm{C}$, the strength dropped off faster than would have been predicted by the master curve fitted through the remaining data.

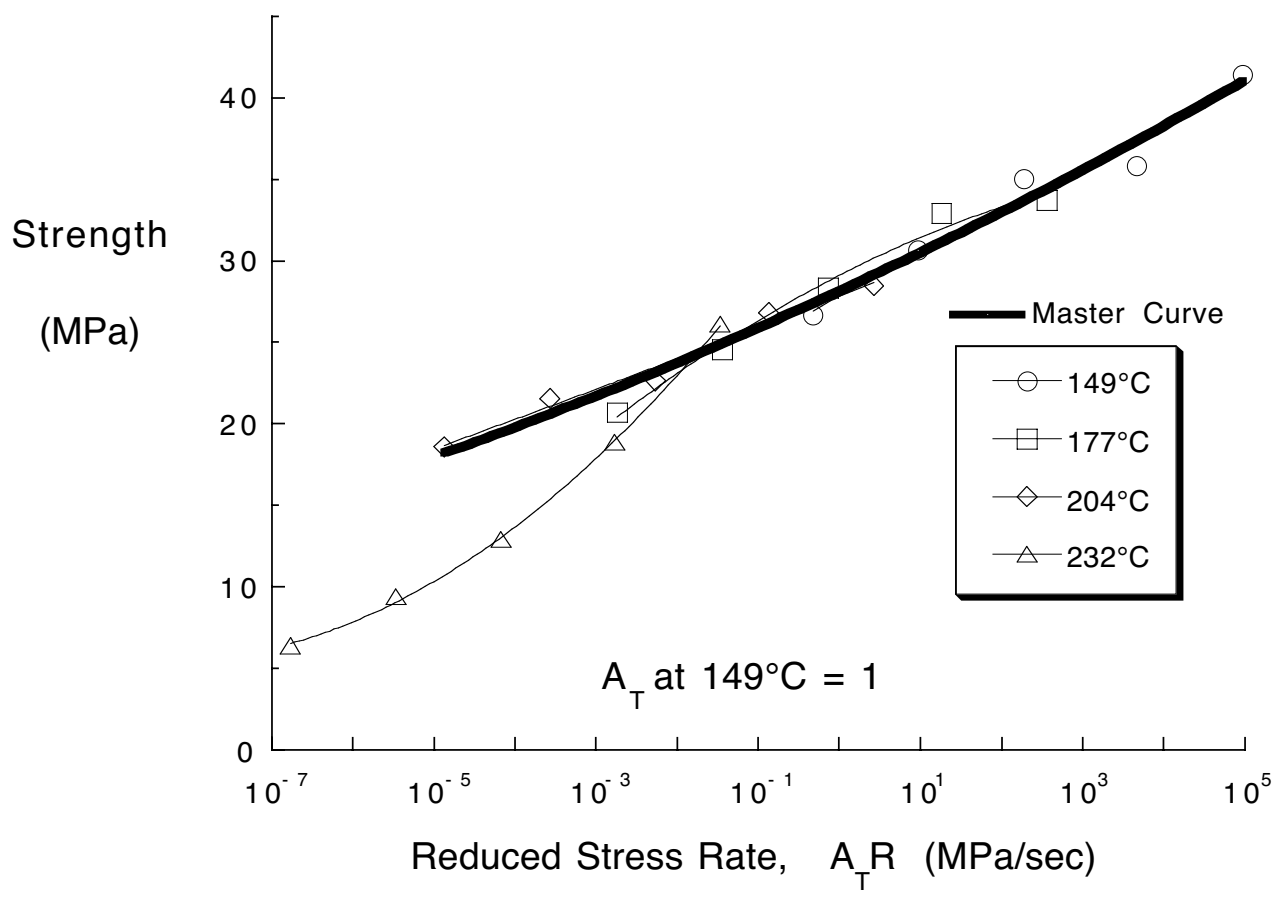

Figure 9. Transverse tension strength results reduced by temperature. 
The formation of the master curve indicates that an increase in temperature creates an effect that is comparable to decreasing the stress rate and therefore increasing the time scale of a test. The formation of a master curve allows the prediction of the $149^{\circ} \mathrm{C}$ strength tested at a stress rate of $10^{-5} \mathrm{MPa} / \mathrm{sec}$ which would require approximately 50 years to conduct. If the $232^{\circ} \mathrm{C}$ data had also followed the master curve, $149^{\circ} \mathrm{C}$ tests conducted at $10^{-7} \mathrm{MPa} / \mathrm{sec}$ could have been predicted which would have required 5000 years to conduct! The current master curve allows predictions of $177^{\circ} \mathrm{C}$ tests lasting half a year while 50 year tests could have been predicted if the $232^{\circ} \mathrm{C}$ tests had also fallen along the master curve.

Although this way of making predictions of strength over long time scales is significant, the technique by itself only allows for accelerating similar load histories at a constant temperature. Additional knowledge would be needed to, for example, use these results to predict creep test data where the stress is held constant until specimen failure or to a predict the strength of a constant ramp tests during which the temperature changed. To better understand how the entire history of load and temperature leading up to failure effects strength, the cause of failure was explored. The development of such understanding could significantly expand the usefulness of strength master curves such as the one presented in Figure 9. Because the shift constant for strength is the same as the shift constant for compliance, it is suspected that the two time dependent effects may be due to the same phenomenon. The change in strength with time may even be caused directly by the change in compliance. The $\mathrm{W}_{\mathrm{f}}$ fracture parameter relates compliance to failure.

\section{Comparison to $W_{f}$ Fracture Model}

Predictions of the $\mathrm{W}_{\mathrm{f}}$ fracture model are shown in Figure 10. The constant $\mathrm{W}_{\mathrm{f}}$ parameter was fit to the data at two different reference strength values. The experimental data in Figure 10 is plotted against temperature reduced stress rate just as it was presented in Figure 9. It is clear from the graph that this simple fracture model does not capture the failure characteristics of the material, and that using a different constant value of $\mathrm{W}_{\mathrm{f}}$ would not help significantly. 


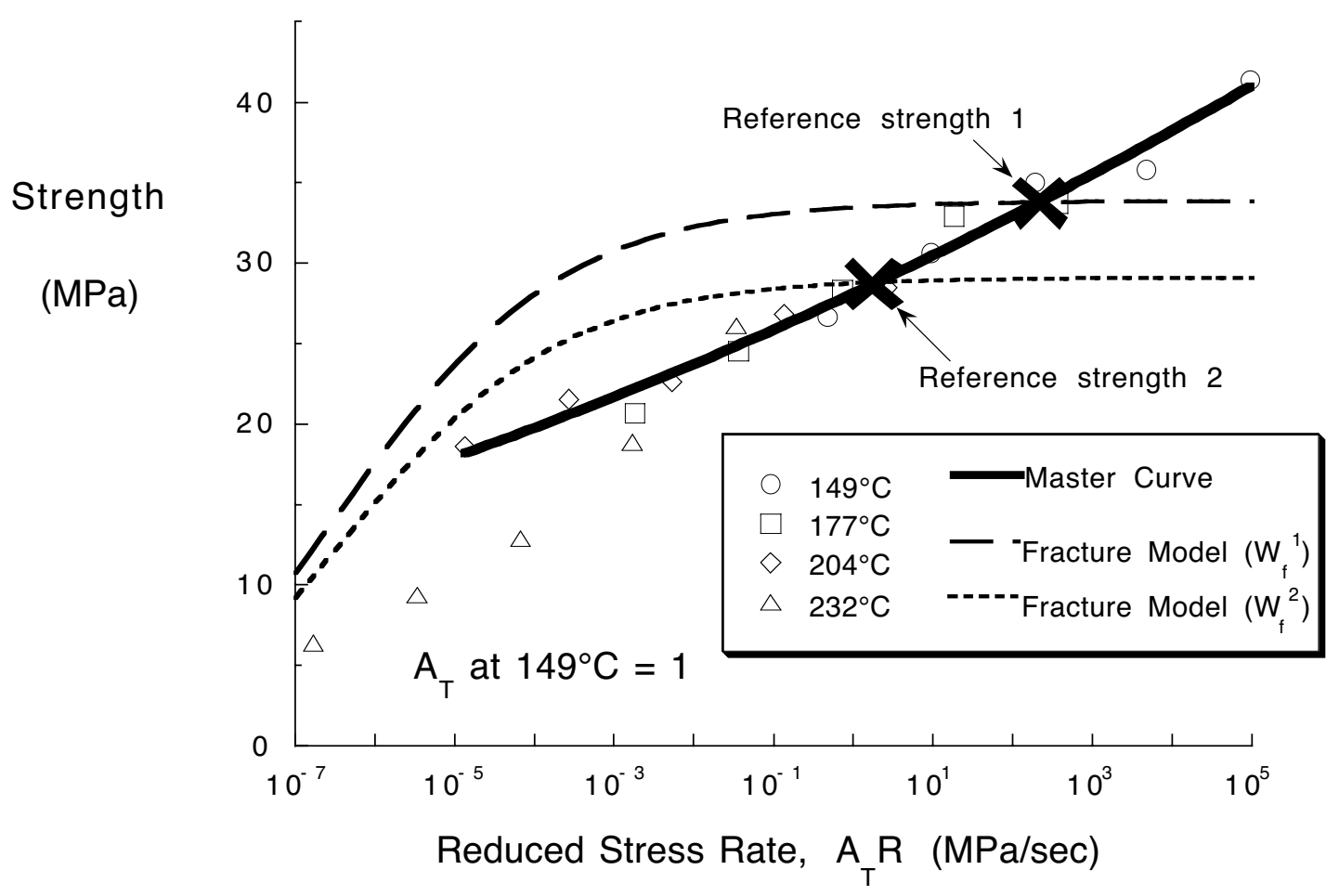

Figure 10. Fracture model fitted to strength results reduced by temperature.

\section{Verification of Compliance Model}

One possible cause of the discrepancy with the $\mathrm{W}_{\mathrm{f}}$ model predictions was that it relied on matrix properties based on neat resin tests. The properties of neat resin can be significantly different from the matrix due to differences in curing when fibers are present or differences in chemistry due to additives in the prepregging process. To test for this difference, the stressstrain response measured during the strength tests were compared to predictions from the composite compliance model. Figure 11 shows these results for the slowest ramp rate at each temperature. The model seems to predict the experimental results quite well at $204^{\circ} \mathrm{C}$ and below, but at $232^{\circ} \mathrm{C}$, the measured compliance is much greater than predicted. The discrepancy might actually be worse than is indicated. At $232^{\circ} \mathrm{C}$, the specimen are shown to be extremely compliant. When measuring strain of such a compliant specimen with a strain gauge, the strain gauge can stiffen the specimen therefore causing the measured compliance to be less than the true response. The failure of the compliance model at $232^{\circ} \mathrm{C}$ is not surprising since it is based on neat resin results with a peak temperature of $225^{\circ} \mathrm{C}$. Extrapolating compliance results near the glass transition temperature where deformation properties are changing very rapidly can cause the 


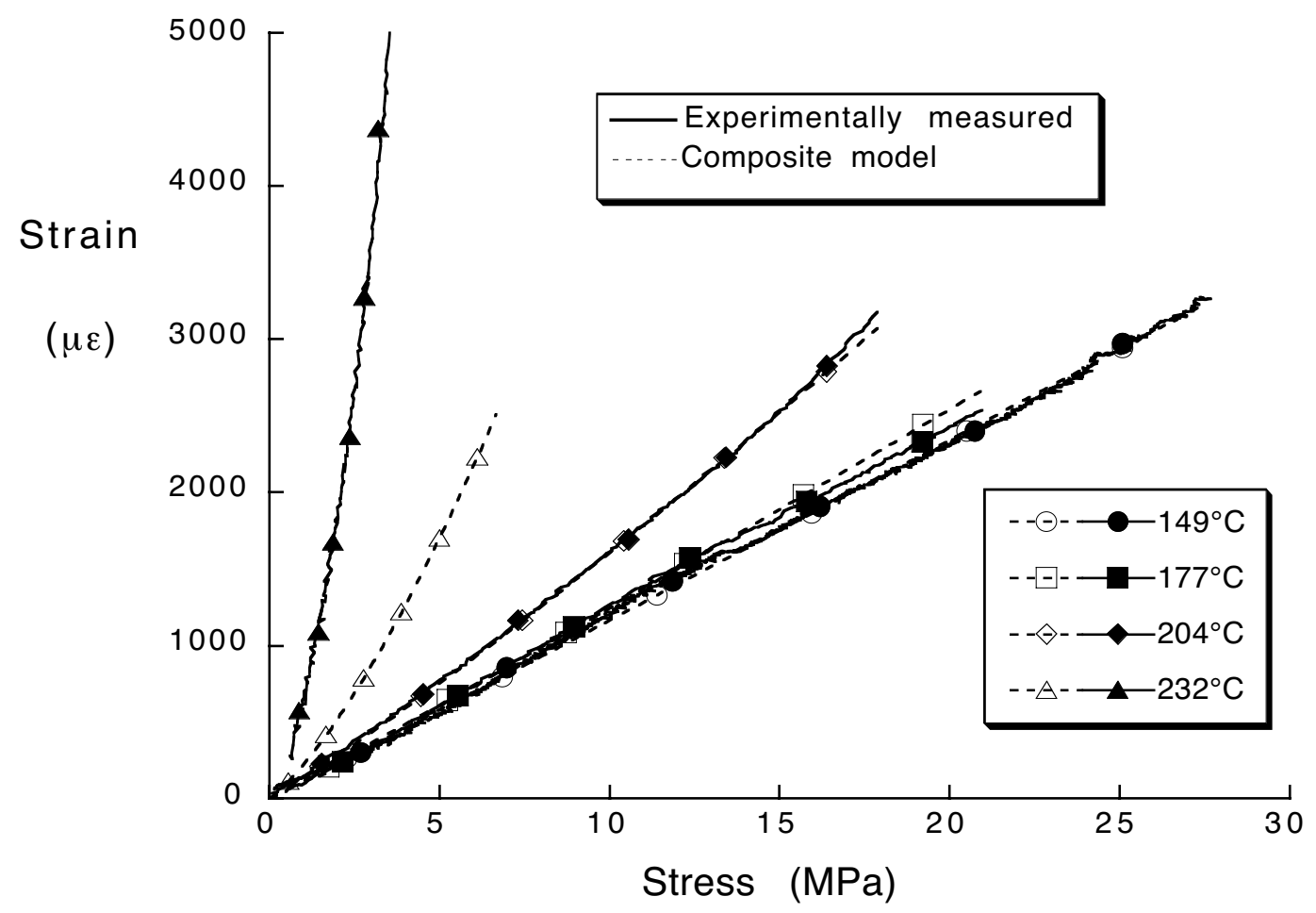

Figure 11. Strain response of slow ramp tests $(0.473 \mathrm{MPa} / \mathrm{sec})$.

large modeling errors observed in this case. The magnitude of the change in K3B properties can be seen in reference 13 where changes in modulus were measured near $T_{g}$. Changing material properties near the glass transition temperature would also be a reason why the $232^{\circ} \mathrm{C}$ strength data does not fall on the master curve created by the strength values at the lower temperatures.

Figure 12 shows the composite compliance model prediction for the $204^{\circ} \mathrm{C}$ tests at all the different stress rates tested. The agreement between the predicted and the measured response indicates that the model captures the time-dependent deformation at this temperature. The compliance model of the composite, and therefore of the matrix, appears to perform well up to $204^{\circ} \mathrm{C}$ so this should not be the reason for the poor agreement between the fracture model strength predictions and the experimentally measured master curve.

\section{Variable $W_{f}$ Model Results}

The fracture model predictions shown in Figure 10 were based on the assumption that the $\mathrm{W}_{\mathrm{f}}$ parameter was not a function of time and temperature. Although there was a significant modeling advantage to making this assumption, it did not produce predictions that matched the material 


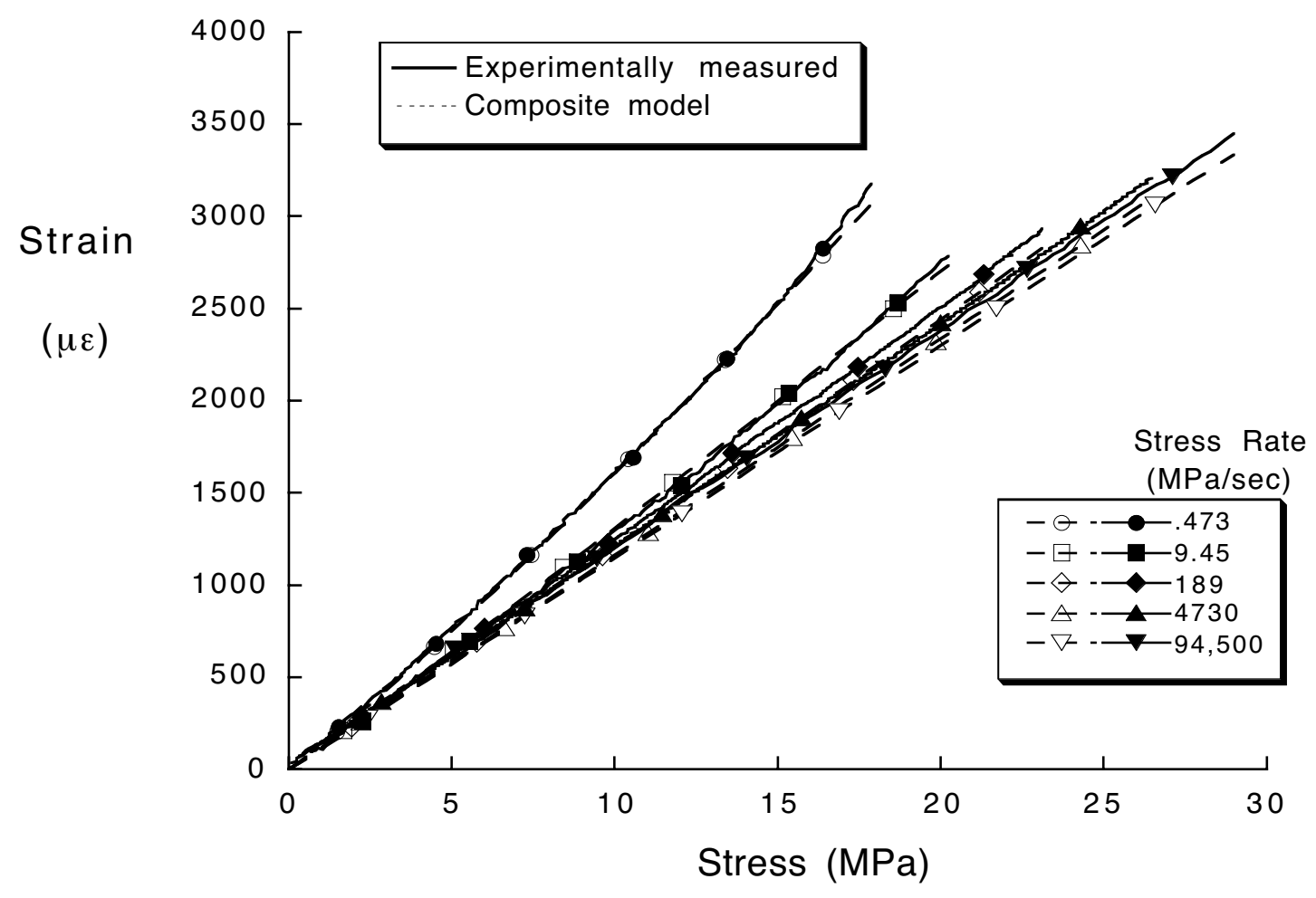

Figure 12. Strain response at $204^{\circ} \mathrm{C}$.

response. To investigate how $\mathrm{W}_{\mathrm{f}}$ might have been changed with time and temperature, a $\mathrm{W}_{\mathrm{f}}$ value was calculated from the average strength at each test condition. These $\mathrm{W}_{\mathrm{f}}$ values were plotted on Figure 13 normalized to the peak value. Only normalized values were possible because the value of $C_{2}$ was not known. Figure 13 indicates that the $\mathrm{W}_{\mathrm{f}}$ parameter did change significantly with temperature reduced stress rate. On this figure where the data were shifted using the shift factors from compliance tests, all data fell along a master curve except for the $232^{\circ} \mathrm{C}$ data. Fitting a line through the remaining data on this log-log plot produces an expression for the $\mathrm{W}_{\mathrm{f}}$ master curve. At $232^{\circ} \mathrm{C}$, the $\mathrm{W}_{\mathrm{f}}$ values shown are in error because they are based on the compliance model which was shown to greatly underestimated the actual deformation of the material at this temperature. If the material compliance were correctly modeled at $232^{\circ} \mathrm{C}$, these $\mathrm{W}_{\mathrm{f}}$ values would be higher bringing them closer to the master curve.

The fact that $\mathrm{W}_{\mathrm{f}}$ appears to be a function of rate may not be a complete surprise if one considers the Dugdale assumption [14] that

$$
\mathrm{G}_{\mathrm{Ic}} \cong \sigma_{\mathrm{F}} \delta_{\mathrm{CTOD}}
$$




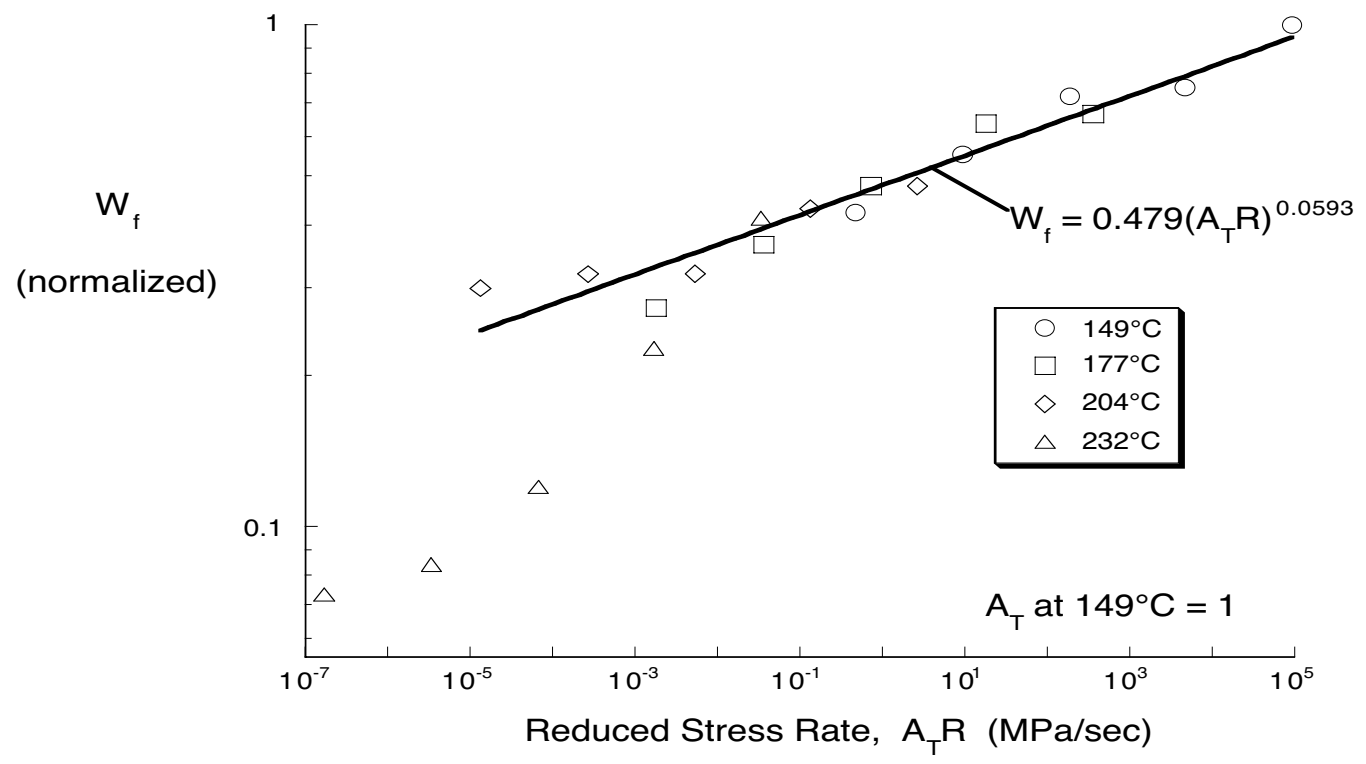

Figure $13 . \mathrm{W}_{\mathrm{f}}$ results from strength tests reduced.

The displacement at the crack tip just prior to crack growth $\left(\delta_{\mathrm{CTOD}}\right)$, has been shown to remain constant over a range of temperatures for certain classes of materials [15]. Assuming TTSP, $\delta_{\text {CTOD }}$ would be constant with time as well. The plastic flow stress $\left(\sigma_{\mathrm{F}}\right)$ for the material at the crack tip might be assumed to increase with increasing stress rates since the creep rupture stress of polymers increases with shorter times to failure [16]. A rate dependence in $\sigma_{\mathrm{F}}$ would produce a rate dependence in $\mathrm{G}_{\mathrm{Ic}}$ and therefore in $\mathrm{W}_{\mathrm{f}}$ which would explain the rate dependence seen in Figure 13.

Because $\mathrm{W}_{\mathrm{f}}$ changed with time and temperature, the predictive capabilities of the fracture model were severely limited, but some predictions were possible because $\mathrm{W}_{\mathrm{f}}$ varied in a way that could be modeled. Using the expression for how $\mathrm{W}_{\mathrm{f}}$ changes with temperature reduced stress rate, predictions were made with the fracture model. Figure 14 shows that the variable $\mathrm{W}_{\mathrm{f}}$ model performed well in modeling the experimental results up to $204^{\circ} \mathrm{C}$, but at $232^{\circ} \mathrm{C}$ where the model is suspect as discussed previously, the model over predicted strength. The fact that the model fits the data up to $204^{\circ} \mathrm{C}$ should not be a surprise since the curve was in fact fitted to the data, just in a transformed space. 


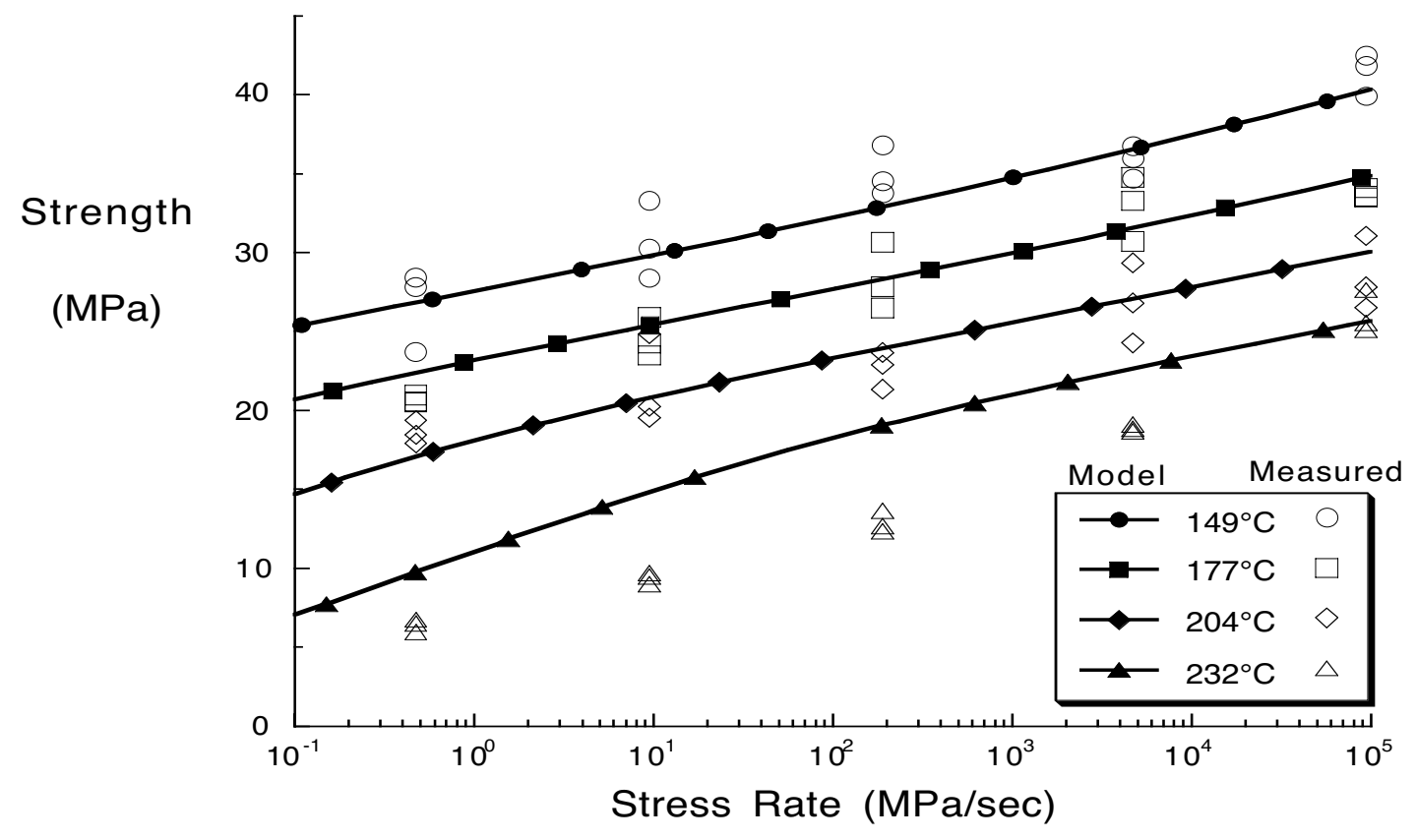

Figure 14. Strength predictions assuming varying $\mathrm{W}_{\mathrm{f}}$

If $\mathrm{W}_{\mathrm{f}}$ is shown to be the controlling parameter for these failures, then this model will allow these results to be used to predict failures of other configurations where fracture is the controlling mechanism. Unfortunately because $\mathrm{W}_{\mathrm{f}}$ proved to be a function of time and temperature, predictions of tests with other types of load-temperature histories could not be predicted without further understanding of how the $\mathrm{W}_{\mathrm{f}}$ parameter changes.

\section{CONCLUDING REMARKS}

The use of time-temperature superposition was shown to apply to the transverse tensile strength of a thermoplastic composite material using the same shift factors as measured for compliance. This was demonstrated with transverse tension strength data for IM7/K3B at four temperatures from $149^{\circ} \mathrm{C}$ to $232^{\circ} \mathrm{C}$ and at five different stress rates that produced failure in the range from $0.5 \mathrm{sec}$ to 24 hours. This accelerated test method applied well up to $204^{\circ} \mathrm{C}$ where a master curve could be formed from the experimental data. The master curve showed that a composite might suffer losses of 50\% in strength when the time scale is increased by 9 orders of magnitude. Results at $232^{\circ} \mathrm{C}$, however, did not fit on the master curve. 
To explain why the same shifts rates might apply to both strength and compliance, a viscoelastic fracture $\left(\mathrm{W}_{\mathrm{f}}\right)$ model was investigated based on the hypothesis that transverse strength is controlled by the work of fracture for crack initiation from a critical flaw. An expression for $\mathrm{W}_{\mathrm{f}}$ based on the viscoelastic $\mathrm{J}$-integral theory and the elastic-viscoelastic correspondence principle was used to relate viscoelastic compliance to strength. Had the $\mathrm{W}_{\mathrm{f}}$ parameter remained constant with time and temperature, the time-dependent nature of strength would have been controlled solely by the time-dependent compliance properties used as input to the model. The model was found to fit the strength data only if $\mathrm{W}_{\mathrm{f}}$ was allowed to vary as a power law in temperature reduced stress rate. The varying $\mathrm{W}_{\mathrm{f}}$ parameter, may limit the ability to extrapolate from one set of experimental results to predictions of failures after arbitrary load and temperature histories.

The significance of this research is therefore seen as providing an indication that a more versatile acceleration method for strength may be possible while also providing the evidence that such a method is needed. The promise of an accelerated test method comes from the strength data forming a master curve. The need for an accelerated test is demonstrated by the significant decrease in strength over the five orders of magnitude in stress rate which were tested.

\section{References}

[1] Ferry, J. D., Viscoelastic Properties of Polymers, Wiley, New York, 1970.

[2] Scott, D. W., Lai, J. S. and Zureick, A.-H., "Creep Behavior of Fiber-Reinforced Polymeric Composites: A Review of the Technical Literature," Journal of Reinforced Plastics and Composites, Vol. 14, 1995, pp. 588-617.

[3] Miyano, Y., Kanemitsu, M., Kunio, T. and Kuhn, H. A., "Role of Matrix Resin on Fracture Strengths of Unidirectional CFRP," Journal of Composite Materials, Vol. 20, 1986, pp. $520-538$.

[4] Mohri, M., Miyano, Y. and Suzuki, M., “Time-Temperature Dependence on Flexural Strength of Pitch-Based Carbon Fiber Unidirectional CFRP Laminates," Composites: 
Design, Manufacture, and Application, S. W. Tsai and G. S. Springer, Eds., Proceedings of ICCM VIII, SAMPE, Honolulu, 1991, pp. 33-B-1 to 9.

[5] Schapery, R. A., “Correspondence Principles and a Generalized J Integral for Large Deformation and Fracture Analysis of Viscoelastic Media," International Journal of Fracture, Vol. 25, 1984, pp. 195-223.

[6] Feldman, M., “The Effects of Elevated Temperature on the Physical Aging of a High Temperature Thermoplastic Resin and Composite," Master's Thesis in Engineering Mechanics, Old Dominion University, Norfolk, VA, 1996.

[7] Gol'dman, A. Y., "Prediction of the Deformation Properties of Polymeric and Composite Materials," M. Shelef and R. A. Dickie, Eds., American Chemical Society, Washington D. C., 1994.

[8] Schapery, R. A., "Viscoelastic Behavior and Analysis of Composite Materials," Ch. 4 of Mechanics of Composite Materials, Vol. 2, Sendeckyj, Ed., Academic Press, New York, 1974.

[9] Broek, D., "The Energy Principle," Ch. 5 of Elementary Engineering Fracture Mechanics, 4th ed., Kluwer Academic Publishers, Boston, 1991, pp. 123-149.

[10] Brockway, G. S. and Schapery, R. A., "Some Viscoelastic Crack Growth Relations for Orthotropic and Prestrained Media," Engineering Fracture Mechanics, Vol. 10, 1978, pp. 453-468.

[11] Reeder, J. R., "Prediction of Long-Term Strength of Thermoplastic Composites Using Time-Temperature Superposition,” Ph.D. Dissertation in Mechanical Engineering, Texas A\&M University, College Station, TX, 1998.

[12] O'Brien, T. K. and Salpekar, S. A., "Scale Effects on the Transverse Tensile Strength of Graphite/Epoxy Composites," Composite Materials: Testing and Design, ASTM STP 1206, Vol. 11, E. T. Camponeschi, Jr., Ed., American Society for Testing and Materials, Philadelphia, 1993. 
[13] Lear, C. M., "Material Characterization of Thermoplastic Candidate Matrix Materials for Advanced Composites," Master's Thesis in Engineering Mechanics, Ohio State University, Columbus, OH, 1994.

[14] Brown, W. F., Jr. and Strawley, J. E., Eds., Plane Strain Crack Toughness Testing of High Strength Metallic Materials, ASTM STP 410, American Society of Testing and Materials, Philadelphia, 1966.

[15] Kinloch, A. J. and Young, S., Flow and Fracture of Polymers, Elsevier, New York, 1985.

[16] Rosato, D. V., DiMattia, D. P. and Rosato, D. V., "Plastics: Design Criteria," Ch. 3 of Designing With Plastics and Composites: A Handbook, Van Nostrand Reinhold, New York, 1991, pp. 125-252. 